\title{
The Management of Paroxysmal Nocturnal Hemoglobinuria- Recent Advances in Diagnosis and Treatment, and New Hope for Patients
}

\author{
Hubert Schrezenmeier, MD and Britta Höchsmann, MD
}

Institute of Transfusion Medicine, University of UIm, and

Institute of Clinical Transfusion Medicine and Immunogenetics UIm, Red Cross Blood Service Baden-Württemberg-Hessen

\begin{abstract}
Paroxysmal nocturnal hemoglobinuria (PNH) is a rare life-threatening and debilitating disorder of hematopoiesis. It is characterized by the clinical triad of Coombs-negative acquired extracorpuscular hemolytic anemia, thrombophilia, and bone marrow failure. The sequelae of intravascular hemolysis drastically affect the quality of life of patients. Cytopenia and in particular thrombophilia can cause life-threatening complications. Thromboembolic events are the major cause of death. The only curative treatment for PNH is allogeneic stem cell transplantation from a related or unrelated stem cell donor. Recent reports demonstrated favorable outcomes. Other treatments were generally supportive in nature. Recently, eculizumab, a humanized monoclonal antibody that inhibits complement factor C5, was approved. It is a targeted, disease-modifying treatment of PNH. This article will summarize major advances in the management of PNH during the last year, and in particular will discuss new results of eculizumab, treatment of thrombosis, and stem cell transplantation. Given the new advances there is hope for improved survival of these patients.
\end{abstract}

\section{Keywords}

Paroxysmal nocturnal hemoglobunuria, stem cell transplantation, eculizumab

Disclosure: The authors have no conflicts of interest to declare.

Received: November 27, 2008 Accepted: June 18, 2009 DOI: 10.17925/OHR.2009.02.0.74

Correspondence: Hubert Schrezenmeier, MD, Chair, Professor of Transfusion Medicine, Institute for Clinical Transfusion Medicine and Immunogenetics UIm, Red Cross Blood Service Baden-Württemberg - Hessen and Institute of Transfusion Medicine University of UIm, Helmholtzstraße 10, 89081 UIm, Germany. E: h.schrezenmeier@blutspende.de

\section{Pathophysiology of Paroxysmal Nocturnal Hemoglobinuria}

Paroxysmal nocturnal hemoglobinuria (PNH) is a non-malignant clonal disorder of hematopoiesis. ${ }^{1}$ The genetic basis is acquired somatic mutations of the X-chromosomal gene PIG-A in one or few hematopoietic stem/progenitor cells. ${ }^{2}$ The protein encoded by PIG-A is essential for the synthesis of the glycosylphosphatidylinositol (GPI) anchor. The GPI moiety serves as the membrane anchor for a group of proteins, known as GPI-anchored proteins. These proteins are functionally diverse, and include CD14, CD16, CD24, CD28, CD48, CD52, CD55, CD58, CD59, CD66c, CD66b, CD73, CD87, CD90, CD108, CD109, CD157, CD317, GP500, GP175, and JMH-bearing protein. ${ }^{3-5}$ The expression of these proteins is either substantially reduced (PNH type II cells) or completely missing (PNH type III cells) on the cells arising from the PIG-A mutated stem or progenitor cell (see Figure 1).

As PIG-A gene mutations in PNH are acquired somatic mutations, not all hematopoietic cells are affected. There is always a mosaic of PIG-A-mutated, GPI-deficient cells and non-PIG-A-mutated cells with normal expression of GPI-anchored proteins (see Figure 1). ${ }^{2}$ Interestingly, clonal populations of hematopoietic cells with PIG-A gene mutation and $\mathrm{GPI}$-anchor deficiency are also present in normal individuals. ${ }^{6,7}$ Selection of GPI-anchor-deficient cells or secondary genetic events in PIG-A-mutated cells might be necessary for the expansion of the $\mathrm{PNH}$ clone(s). ${ }^{8}$

Measurement of expression of the GPI-anchored proteins by flow cytometry has become the gold standard for laboratory diagnosis of $\mathrm{PNH}$ and has replaced the Ham test and the sucrose lysis test (sugar water test) ${ }^{5.9}$ Flow cytometry allows sensitive and specific detection of even small GPI-deficient populations and a quantitative assessment of the size of the PNH cell population in various cell lineages, and can be used for both initial diagnosis and monitoring during follow-up., ${ }^{3,40-12}$

Clinically, PNH is characterized by the triad of acquired coombsnegative intracorpuscular hemolytic anemia, thrombophilia, and bone marrow failure. 19,13 The clinical presentation and the course of the disease are highly variable. Many of the clinical features of PNH can be attributed to the deficiency of the GPI-anchored proteins: two GPIanchored proteins (CD55, CD59) are important for regulation of complement. Absence of these proteins from the surface of $\mathrm{PNH}$ red blood cells (RBCs) renders them susceptible to terminal complementmediated lysis. CD59 blocks the terminal complement complex (membrane attack complex). Due to the absence of CD55 and CD59, $\mathrm{PNH}$ RBCs are highly sensitive to complement-mediated hemolysis. Severe hemolysis occurs predominantly in situations where 
Figure 1: Flow Cytometric Analysis of Expression of Glycosylphosphatidylinositol-anchored Proteins on Granulocytes

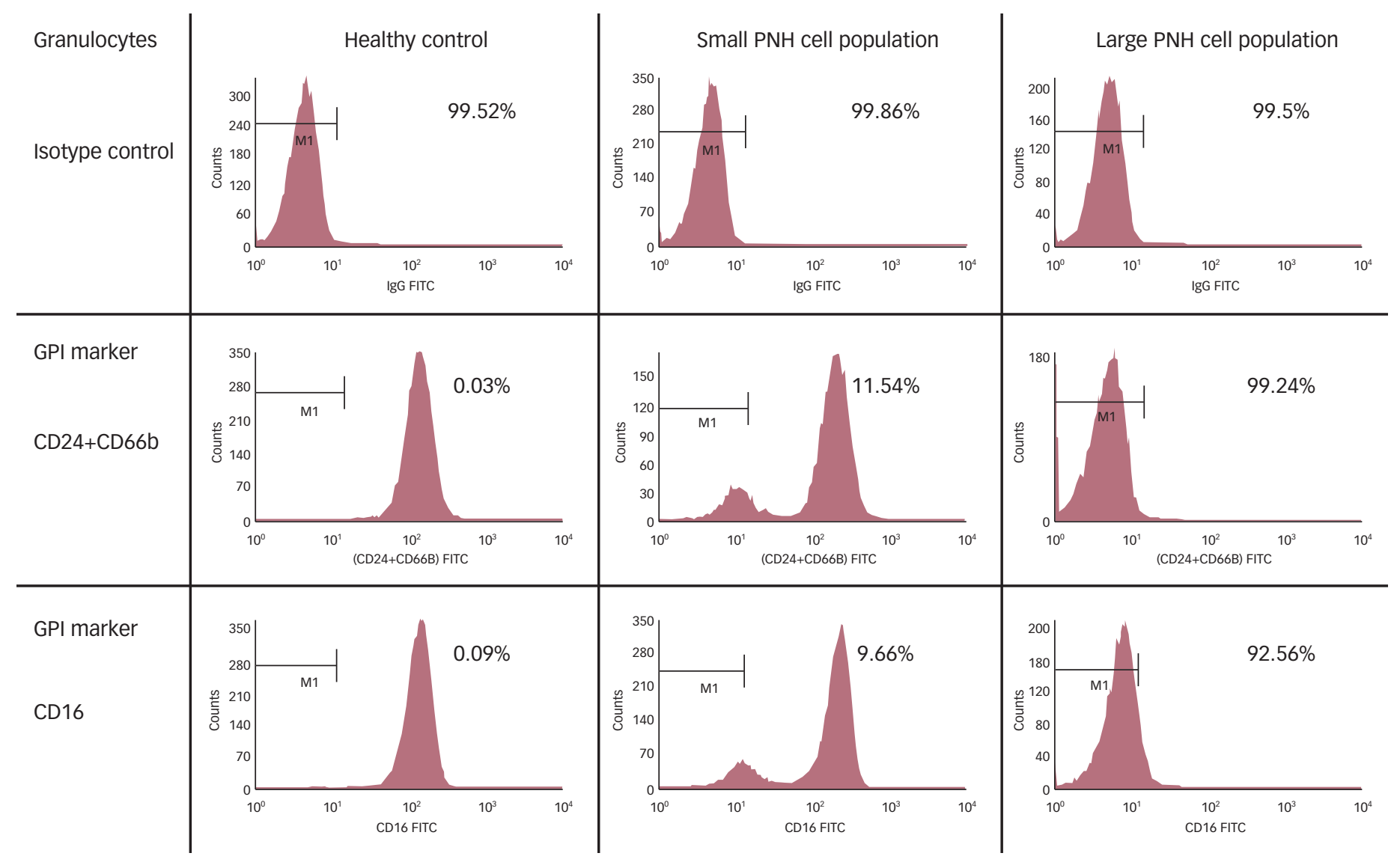

Normal control (left column) and patients with small (middle column) or large glycosylphosphatidylinositol (GPI)-deficient cell population (left column). $P N H=$ paroxysmal nocturnal hemoglobinuria; IgG = immunoglobulin G; FITC = fluorescein isothiocyanate.

complement activation is enhanced, thus in most instances these hemolytic crises occur in the context of infections, surgery, trauma, or pregnancy. Chronic hemolysis with hemosiderinuria leads to iron deficiency in many patients. 14,15

Thrombophilia is the leading cause of mortality in $\mathrm{PNH}$. Thrombosis in $\mathrm{PNH}$ will occur in about $50 \%$ of patients with hemolytic $\mathrm{PNH} .{ }^{9,13,16,17}$ Thrombosis can occur anywhere; however, thrombosis often occurs at 'unusual' sites such as hepatic, portal, splenic and mesenteric, cerebral, and dermal veins. ${ }^{9,16}$ The risk for thromboembolic events seems to be directly related to the size of the PNH cell population (as measured by GPI-deficient granulocytes). ${ }^{12,16,18}$ In the study of Moyo et al., the odds ratio for risk for thrombosis was estimated to be 1.64, according to logistic regression modeling for a $10 \%$ change in $\mathrm{PNH}$ clone size. ${ }^{12}$ No patient with $<61 \%$ PNH granulocytes developed a thrombosis, whereas 12 of 22 patients (54.5\%) with $\geq 61 \%$ PNH granulocytes manifested with thrombosis. ${ }^{12}$ In the study of Hall et al., the 10-year risk for thrombosis was $5.8 \%$ in patients with $<50 \%$ GPI-deficient granulocytes versus $44 \%$ in patients with $>50 \% \mathrm{GPI}$-deficient granulocytes. ${ }^{16}$ The cause of thrombophilia in PNH is multifactorial (see Table 1). ${ }^{19}$ The scavenging of nitric oxide (NO) by free hemoglobin is a crucial event, ${ }^{20}$ contributing to both thrombosis and other PNH-related symptoms. Hemoglobin released from RBCs during hemolysis binds to haptoglobin, which is rapidly cleared from the circulation via binding to CD163. ${ }^{21}$ When the capacity of this hemoglobin-scavenging protein is saturated, free hemoglobin appears in the circulation and reacts with NO to produce nitrate $\left(\mathrm{NO}_{3}\right)$ and methemoglobin. ${ }^{22}$ In addition, hemolysis releases arginase from $\mathrm{RBCS}^{23}$ This enzyme converts L-arginine, the substrate for NO synthesis, to ornithine. A profound degree of NO consumption has been demonstrated in $\mathrm{PNH}$ patients. ${ }^{24} \mathrm{NO}$ is a major regulator of smooth-muscle tonus, influences platelet function, and interacts with components of the coagulation cascade. ${ }^{25}$ Decreased NO signaling via cyclic guanosine monophosphate (cGMP) leads to increased smoothmuscle tonus, which can result in typical symptoms of $\mathrm{PNH}$, e.g. abdominal pain, dysphagia, erectile dysfunction, and pulmonary hypertension. NO depletion also increases platelet aggregation, inhibits disaggregation of aggregated platelets, and induces platelet adhesion, which together with local vasoconstriction contribute to thrombophilia (see Figure 2). Recent studies have demonstrated that there is a high incidence of progression to chronic renal insufficiency in patients with $\mathrm{PNH}$. Renal damage in PNH has been associated with chronic hemolysis and subsequent hemosiderosis and/or microvascular thrombosis. ${ }^{25}$

Progressive pancytopenia occurs in a proportion of PNH patients. In a recent study of a large cohort of patients in France, the cumulative 10-year incidence of bicytopenia or pancytopenia was $19.2 \% .^{9}$ In 
Table 1: Multifactorial Pathogenesis of the Thrombotic Tendency in Paroxysmal Nocturnal Hemoglobinuria

Scavenging of NO by free hemoglobin: ${ }^{19}$

NO inhibits platelet aggregation/adhesion and induces disaggregation (through increasing cGMP levels) ${ }^{83}$

NO inhibits factor XIIII

NO reduction leads to increase in fibrinogen split products and thrombin-

antithrombin complexes ${ }^{84}$

Platelet activation by free hemoglobin ${ }^{85}$

Inhibition of ADAMTS13 by free hemoglobin ${ }^{86}$

Platelet vesiculation/microvesicles ${ }^{8,88}$

Increased membrane prothrombinase complex sites; increased rate of

prothrombin conversion

Exposure of internal red blood cell membrane

Increased proportion of activated platelets (due to CD59 deficiency) ${ }^{89}$

Detachment of urokinase-type plasminogen activator receptor (urokinase receptor [CD87] - a GPI-linked protein) $)^{90}$ and reduced fibrinolytic activity ${ }^{91}$

$N O=$ nitric oxide; $C G M P=$ cyclic guanosine monophosphate; $G P I=$ glycosylphosphatidylinositol.

Figure 2: Consequences of Nitric Oxide Depletion by Intravascular Hemolysis

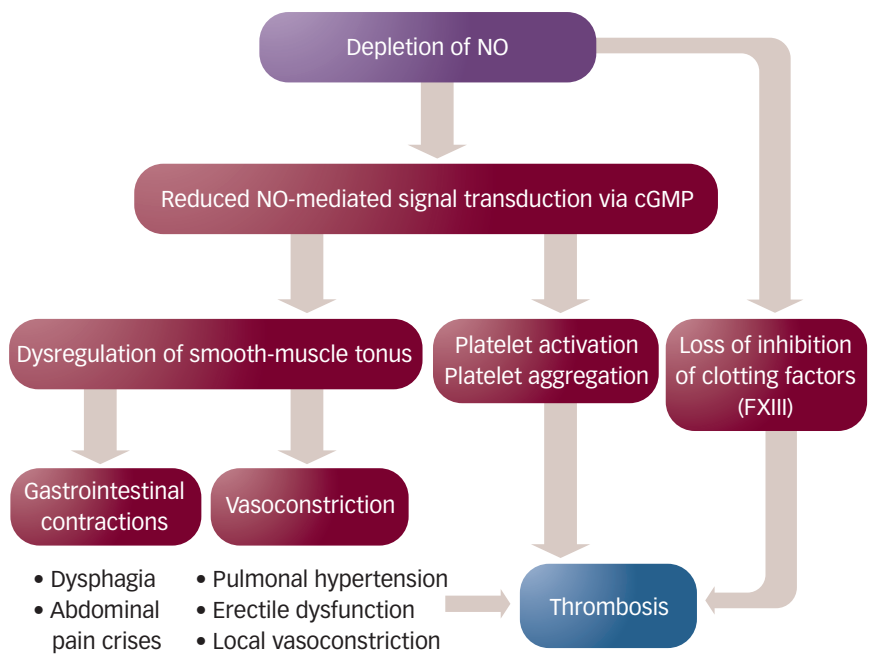

$N O=$ nitric oxide $; C G M P=$ cyclic guanosine monophosphate.

contrast, a substantial proportion of patients (30-50\%) who were initially diagnosed with otherwise typical aplastic anemia (AA) have small proportions of GPI-deficient cells. ${ }^{26-28}$ In a long-term follow-up of a cohort of AA patients, the cumulative incidence of clinical PNH was $13 \% .{ }^{29}$ Furthermore, multiple mutations of the PIG-A gene have been demonstrated in patients with otherwise typical $A A^{30}$

In order to reflect the variations in presenting features, clinical manifestations, and links to other disorders, the International $\mathrm{PNH}$ Interest Group (IPIG) proposed to classify the disease as classic PNH, $\mathrm{PNH}$ in the setting of another specified bone marrow disorder, or subclinical $\mathrm{PNH}{ }^{1}$

\section{Management of Paroxysmal Nocturnal Hemoglobinuria-General Aspects}

Until recently, only two general treatment approaches were available: either stem cell transplantation, which had potential to cure but high
Table 2: Approaches for Treatment of Paroxysmal Nocturnal Hemoglobinuria

\section{Curative Treatment}

Allogeneic stem cell transplantation:

Related and unrelated donors, conventional or reduced intensity conditioning (see Tables 3 and 4)

\begin{tabular}{l} 
Non-curative Treatment \\
Supportive treatment: \\
Red blood cell transfusions (as required based on symptoms) \\
Folic acid supplementation \\
Iron replacement (as required based on iron stores) \\
Treatment of complications when they occur, e.g. thrombosis \\
Prophylactic anticoagulation \\
Prevention/early treatment of infections \\
Non-targeted therapies of PNH-related problems: \\
$\quad$ Corticosteroids \\
$\quad$ Androgens \\
$\quad$ Hematopoietic growth factors: erythropoiesis-stimulating agents, G-CSF \\
$\quad$ High-dose cyclophosphamide \\
Immunosuppressive Treatment \\
In AA-PNH syndrome with severe bone marrow failure requiring treatment \\
\hline Targeted Therapy \\
Complement inhibition by eculizumab \\
Replacement of complement regulatory proteins on PNH cells (not yet available \\
for patients) \\
\hline Gene therapy (not yet available for patients) \\
\hline PNH = paroxysmal nocturnal hemoglobinuria; G-CSF = granulocyte-colony-stimulating factor; \\
AA = aplastic anemia.
\end{tabular}

treatment-related morbidity/mortality, or symptomatic treatment and prophylaxis of complications, which led to unsatisfactory long-term control of the disease. ${ }^{1,31}$ Thus, there was a need for new treatments to be developed. As the clinical symptoms of $\mathrm{PNH}$ are due to increased complement sensitivity of blood cells, inhibition of complement was a logical approach. Eculizumab, a monoclonal antibody that inhibits complement protein $\mathrm{C}_{5}$, is the first and so far only specific complement inhibitor approved for clinical use in $\mathrm{PNH}$. Stem cell transplantation and eculizumab treatment will be discussed in more detail below.

Therapeutic options for PNH are listed in Table 2. Patients with ongoing hemolysis and erythroid hyperplasia should receive folic acid supplementation. Iron stores need careful monitoring. Iron repletion, preferentially by oral administration, should be performed.

RBC transfusion should be performed as required based on symptoms of anemia. The transfused RBCs are resistant against complementmediated lysis. They may even transfer CD55 and CD59 via microvesicles to the recipient GPI-deficient red cells. ${ }^{32}$ Iron overload is unlikely in classic hemolytic $\mathrm{PNH}$, but could occur in $\mathrm{AA}-\mathrm{PNH}$ syndrome. Transfusion requirements can greatly vary from patient to patient in the course of the disease (e.g. depending on the frequency and severity of hemolytic crises due to infections). Leukocyte-reduced RBCs with fewer than $1 \times 10^{6}$ residual leukocytes per unit should be used. Washing of RBCs is not recommended. ${ }^{33}$ It is controversial whether blood products for $\mathrm{PNH}$ patients should be irradiated. 
A substantial subgroup of $\mathrm{PNH}$ patients has concurrent $\mathrm{AA}$ or will develop AA. Therefore, it must be determined how much of the anemia is due to hemolysis and how much is due to bone marrow failure. Immunosuppressive treatment as established for AA (antithymocyte globulin, cyclosporine A) can improve the impaired hematopoiesis that occurs in hypoproliferative $\mathrm{PNH}$, but the hemolytic component of the disease is not altered by immunosuppressive therapy. ${ }^{34,35}$ The effect of immunosuppression on the size of the $\mathrm{PNH}$ clone is equivocal. Both expansion and decrease, and even disappearance, of PNH cells during immunosuppression have been observed. ${ }^{11,35,36}$

Androgens have been successfully used to treat anemia in $\mathrm{PNH} .{ }^{9,14}$ Corticosteroids can be used to attenuate hemolytic exacerbations; however, only some patients respond to steroids. ${ }^{14,37-39}$ Given the inconsistent response and their toxicity profile, it is debatable whether corticosteroids and androgens should be used for long-term treatment. ${ }^{\prime}$ Careful evaluation in terms of convincing evidence for beneficial effects in the individual patient is necessary, and monitoring is essential.

Levels of erythropoietin and granulocyte-colony-stimulating factor (G-CSF) are markedly elevated in $\mathrm{PNH}^{.00,41}$ Therefore, it has been questioned whether there is an indication for growth factors in $\mathrm{PNH}$ treatment at all, ${ }^{40}$ however, in some patients improvement of anemia could be achieved by treatment with erythropoietin. ${ }^{38,42-45} \mathrm{In}$ anecdotal cases, the course of GPI-AP-deficient cells suggests that the efficacy of erythropoietin can be due to either a preferential action on normal cells or the GPI-deficient erythroid clone.42,44 In particular, erythropoietin may be a suitable adjunct in patients who have reduced hemolysis during eculizumab treatment (see below), but who are still transfusion-dependent. ${ }^{46}$

In patients with hypoplastic PNH, a combination of G-CSF and cyclosporin can improve cytopenia and reduce the number of GPI-APdeficient cells. ${ }^{47}$ In eculizumab-treated patients with reduced hemolysis who are still transfusion-dependent, promotion of erythropoiesis by addition of erythropoiesis-stimulating factors may further improve hemoglobin and render patients transfusion-independent, in particular in $\mathrm{PNH}$ with underlying bone marrow failure. ${ }^{46}$ Other approaches so far studied in animal models and not yet available for clinical treatment are the replacement of complement inhibitory proteins in PNH cells and gene therapy. Alternative artificial glycolipid anchors or single-chain antibody fragments (SCFV) were used to anchor CD59 into the cell membrane (Prodaptin-CD59 and ScFV-DAF), which restores resistance of $\mathrm{PNH}$ cells to complement in vitro. ${ }^{48,49}$

\section{Curative Treatment-Allogeneic Stem Cell Transplantation}

Allogeneic stem cell transplantation is the only treatment with curative potential. ${ }^{1}$ However, due to the high transplant-related morbidity and mortality, only a small group of PNH patients have been transplanted in the past. ${ }^{1,31}$ For example, only 268 allogeneic stem cell transplants were reported to the Registry of the European Group for Blood and Marrow Transplantation (EBMT) between 1978 and 2007..$^{50}$

According to the recommendation of the IPIG criteria for consideration of transplantation are bone marrow failure (fulfilling criteria of severe aplastic anemia) or major complications of $\mathrm{PNH}$, i.e. recurrent lifethreatening thromboembolic disease or refractory, transfusiondependent hemolytic anemia.

Published single-center experience using either conventional| ${ }^{51-61}$ or reduced-intensity conditioning ${ }^{62-67}$ is summarized in Tables 3 and 4 . Great heterogeneity of results exists, with the probability of overall survival ranging from $<60$ to $100 \%$. Recent studies using reducedintensity conditioning reported very favorable results. In retrospective analyses of registry data, overall survival after human leukocyte antigen (HLA)-identical sibling transplant for PNH was 56\% at two years (International Bone Marrow Transplant Registry [IBMTR]) ${ }^{31}$ or $70 \%$ at five years (EBMT). ${ }^{50}$ The substantial differences in outcome most likely represent the heterogeneity in indication, timing of transplant, concurrent aplastic anemia, or complications (e.g. BuddChiari) present at the time of transplant. There is no evidence that results with matched unrelated donors are inferior to those with HLAmatched sibling transplants. For PNH-aplastic anemia syndrome, a conditioning regimen of cyclophosphamide and antithymocyte globulin (ATG) is recommended. ${ }^{1}$ For patients with classic $\mathrm{PNH}$, the best regimen-in particular the role of reduced-intensity regimensneeds to be determined.

Unsatisfactory results are not due to relapse of $\mathrm{PNH}$, which is a very rare event (see Tables 3 and 4). Transplant-related mortality is the major problem that needs to be addressed. In particular, future studies must address indications for stem cell transplantation, optimization of conditioning regimens, and donor selection.

\section{Disease-modifying Treatment-Eculizumab}

Eculizumab (Soliris ${ }^{\circledR}$, Alexion Pharmaceuticals) is a humanized monoclonal immunoglobulin (IgG)- $2 / 4 \mathrm{~K}$ antibody directed against the terminal complement protein C5. Eculizumab contains the murine complementarydetermining regions of m5G1.1 mAb, which were grafted onto the human framework light- and heavy-chain variable regions to minimize the potential for immunogenicity. ${ }^{68,69}$ Eculizumab binds to the complement protein C5 with high affinity and inhibits its cleavage to C5a and C5b, thereby preventing the generation of the terminal complement complex C5b-C9.68,69 Blockade of C5 completely blocks the terminal complement cascade with formation of the membrane attack complex irrespective of the pathway of complement activation. However, it does not interfere with the generation of components in the early steps of complement activation, which generate important mediators for immunoregulation and protection against infections.

Eculizumab has been evaluated in three separate trials in $\mathrm{PNH}$ patients. ${ }^{70-75}$ The first pilot study enrolled 11 patients with hemolytic $\mathrm{PNH}_{,}{ }^{71,75}$ and two phase III trials enrolled another 184 patients. ${ }^{70,72}$ The first phase III trial, TRIUMPH, was a double-blind, randomized, placebocontrolled, multicenter trial that examined safety and efficacy in hemolytic PNH patients who had received at least four transfusions in the four months prior to enrolment and a platelet count $>100 \times 10^{9} / \mathrm{I}^{74}$ SHEPHERD was an open-label, non-placebo-controlled trial that examined eculizumab in a more heterogenous $\mathrm{PNH}$ patient population. ${ }^{70}$ Patients were required to have received at least one transfusion in the previous two years. A platelet count of $\geq 30 \times 10^{9} / /$ was 
Table 3: Summary of Single-center Experience of Allogeneic Stem Cell Transplants Using Conventional Conditioning

\begin{tabular}{|c|c|c|c|c|c|c|c|c|}
\hline Number & AA & Donor & aGvHD & CGVHD & $\begin{array}{l}\text { Outcome } \\
\text { Survival }\end{array}$ & $\begin{array}{l}\text { Probability } \\
\text { of Survival }\end{array}$ & Relapse & Author \\
\hline 1 & 1 & 1 HLA-identical sibling & & & 1 alive & & None & de Souza, $1992^{52}$ \\
\hline \multirow[t]{2}{*}{9} & 6 & 6 HLA-identical siblings & $3 / 9$ grade $\|$ & $4 / 8$ & 8 & & 3а & Kawahara et al., $1992^{54}$ \\
\hline & & 2 twins/ 1 haploidentical & & & FU 10.2 years & & & \\
\hline \multirow[t]{2}{*}{16} & 6 & HLA-identical sibling & $5 / 16$ grade $\|$ & $2 / 14$ & 9 alive & $58 \%$ (5 years) & None & Bemba et al., $1999^{51}$ \\
\hline & & & & $3 / 16$ grade III & & & & \\
\hline \multirow[t]{2}{*}{7} & 4 & HLA-identical sibling & $3 / 7$ grade $\|$ & $7 / 7$ & 7 alive & $100 \%$ & None & Raiola et al., $2000^{55}$ \\
\hline & & & 1/7 grade III & & & & & \\
\hline \multirow[t]{2}{*}{3} & 3 & 3 unrelated donors & & & 3 alive & & None & Woodard et al., $2001^{60}$ \\
\hline & & & & & FU 30-62 months & & & \\
\hline \multirow[t]{2}{*}{2} & 2 & 2 unrelated donors & $2 / 2$ grade $\|$ & & 2 alive & & None & Flotho et al., $2002^{53}$ \\
\hline & & & & & $\mathrm{FU}+22 /+36$ months & & & \\
\hline \multirow[t]{2}{*}{5} & 2 & 3 HLA-identical siblings & $1 / 5$ grade $\|$ & $4 / 4$ & 4 alive & & None & Lee et al., $2003^{57}$ \\
\hline & & 1 unrelated donor & $1 / 5$ grade III & & FU 17-37 months & & & \\
\hline $1^{b}$ & - & 1 HLA-identical sibling & $0 / 1$ & 0/1 & 1 alive & & None & Ditschkowski et al., $2003^{58}$ \\
\hline \multirow[t]{2}{*}{8} & - & 6 family donors & $0 / 8$ & $1 / 8$ & $7 / 8$ & $85 \%$ & None & von Harsdorf et al., $2003^{61}$ \\
\hline & & 2 unrelated donors & & & & & & \\
\hline \multirow[t]{2}{*}{2} & & 2 unrelated donors & & & 2 alive & & None & Markiewicz et al., 2005 \\
\hline & & & & & $\mathrm{FU}+4 /+12$ months & & & \\
\hline
\end{tabular}

Data published since 1992, without syngeneic transplants. a. two relapsing patients received no conditioning; $A A=$ aplastic anemia; aGvHD = acute graft-versus-host disease; cGVHD = chronic graft-versus-host disease; HLA = human leukocyte antigen; FU = follow-up.

Table 4: Summary of Single-center Experience on Allogeneic Stem Cell Transplant Using Reduced-intensity Conditioning

\begin{tabular}{|c|c|c|c|c|c|c|c|c|}
\hline Number & Pancytopenia & Donor & Engraftment & aGvHD & cGVHD & Remission & Survival & Author \\
\hline 1 & 0 & HLA-identical sibling & $1 / 1$ & NR & NR & $1 / 1$ & $1 / 1$ & Suenaga et al., $2001^{64}$ \\
\hline 7 & 1 & $\begin{array}{l}2 \text { related } \\
5 \text { unrelated }\end{array}$ & $7 / 7$ & $5 / 7$ grade $\|$ & $5 / 6$ & $7 / 7$ & $4 / 7$ & Hegenbart et al., $2003^{63}$ \\
\hline 1 & 0 & & & $1 / 1$ & NR & NR & $0 / 1$ & Grosskreutz et al., $2004^{62}$ \\
\hline 5 & 3 & 5 related & $5 / 5$ & $\begin{array}{l}1 / 5 \text { grade III } \\
1 / 5 \text { grade IV }\end{array}$ & $3 / 5$ & $5 / 5$ & $5 / 5$ & Takahashi et al., 20045 \\
\hline 12 & 3 & HLA-matched relative & $12 / 12$ & $6 / 12$ grade $\|$ & $4 / 12$ & $12 / 12$ & $12 / 12^{*}$ & Srinivasan et al., $2006^{66}$ \\
\hline 3 & 1 & 2 haploidentical donors & & $0 / 2$ & $0 / 2$ & & $2 / 2$ & Brodsky et al., 2008 \\
\hline
\end{tabular}

Data published since 1992, without syngeneic transplants. *Survival 77\% in a combined cohort of aplastic anemia (AA) and paroxysmal nocturnal hemoglobinuria (PNH) patients ( $\mathrm{n}=26$ ). aGVHD = acute graft-versus-host disease; cGVHD = chronic graft-versus-host disease; HLA = human leukocyte antigen; NR = not reported.

required. In both trials, lactate dehydrogenase (LDH) levels of 1.5 times the upper limit of normal and a PNH type III RBC population of $10 \%$ or more were required. ${ }^{70,72}$

In all trials, a significant reduction of hemolysis as measured by LDH was observed across all treated participants. The reduction was observed after one week of treatment and was maintained throughout the whole treatment period. Control of chronic hemolysis in the PNH patients resulted in a decrease in transfusion requirements. In the TRIUMPH and SHEPHERD trials, $51 \%$ of patients achieved transfusion independence, and in both trials the transfusion requirements decreased significantly. In eculizumab-treated patients in whom transfusion independence was not achieved, transfusion requirements were reduced by $44 \%$ (data from TRIUMPH study) ${ }^{74}$ The reduction in intravascular hemolysis in the eculizumab group resulted in an increase in PNH type III erythrocytes, whereas the proportion of PNH type III granulocytes and monocytes did not change significantly. ${ }^{70,73,74}$ This means that a higher proportion of erythrocytes is vulnerable against complement-mediated Iysis. In 16 patients from the clinical trial who discontinued eculizumab for various reasons, no serious rebound hemolysis was observed. However, patients should be closely monitored for at least eight weeks in cases of eculizumab discontinuation.

As eculizumab does not block the early stages of complement activation, C3 cleavage products are formed and bind to CD55/CD59-deficient RBCs. The inhibition of terminal membrane attack complex formation by eculizumab allows the survival of these cells, which otherwise would undergo a rapid intravascular hemolysis due to $c 5 b-9$ formation. A positive direct antiglobulin test due to C3d loading (and in some cases also C3c loading of PNH RBCS) seems to be a consistent finding during eculizumab treatment. ${ }^{92}$ This explains mild ongoing hemolysis via extravascular sequestration of RBCs loaded with C3 cleavage product.92 Normalization of hemoglobin after splenectomy in a patient with eculizumab treatment and ongoing extravasal hemolysis has been reported.7 ${ }^{76}$

The immediate and sustained improvement in hemolysis had an impact on fatigue as measured by the Functional Assessment of Chronic Illness Therapy (FACIT)-Fatigue instrument: fatigue improved within one week 
of eculizumab treatment and this was maintained throughout the entire study period. The improvement of fatigue in the eculizumab-treated patients was observed regardless of baseline LDH levels. ${ }^{73}$ The eculizumab-treated patients also had significant improvements in terms of the European Organization for Research and Treatment of Cancer Core Questionnaire Quality of Life Questionnaires (EORTC QLQ-C30) on the scale for global health status, as well as in scales for functioning (role, social, cognitive, physical, and emotional functioning scale) and in two symptom scales (fatigue, pain). ${ }^{70,74}$ These improvements occurred without complete resolution of anemia. Furthermore, patients who did not achieve complete transfusion independence during eculizumab treatment experienced significant improvements in quality of life and fatigue. ${ }^{73}$ This provides further evidence that the diminished quality of life in $\mathrm{PNH}$ is also due to intravascular hemolysis and does not just reflect the severity of anemia.

In general, eculizumab was safe and well tolerated..$^{70,74}$ The most common adverse events reported in the eculizumab-treated patients were headache, nasopharyngitis, back pain, and nausea. The headaches occurred within the first 24 hours after administration of the first two doses of eculizumab. Headache decreased after the first two doses of eculizumab. The headache after start of treatment may be related to a sudden increase of NO due to effective blockade of intravascular hemolysis and therefore cessation of NO scavenging by free hemoglobin. The decrease in headache after the first two doses may indicate a return of NO to physiological levels. ${ }^{70,74}$

Recently, a desquamating rash and hyperammonemia was reported in a patient following the first administration of eculizumab ${ }^{\cdot 77}$ the causality in this case is not clear and a drug-drug interaction with trimethprimsulfamethoxazole was assumed. ${ }^{77}$ As the experience so far with eculizumab in this rare disease is limited, physicians must be vigilant for unexpected adverse events. It is known that individuals with inherited terminal complement deficiency have an increased risk for meningococcal infections. In eculizumab-treated patients, three cases of Neisseria meningitis infections have been reported. ${ }^{78}$ Across all $\mathrm{PNH}$ studies, infections did not seem to be more frequent in patients with eculizumab treatment compared with patients who received placebo. ${ }^{70,74}$

Eculizumab is administered between 25 and 45 minutes as an intravenous infusion according to the following dosing schedule: an induction dose of 600mg every seven $( \pm 2)$ days for four weeks, followed one week later by a $900 \mathrm{mg}$ dose, and then 900mg every $14( \pm 2)$ days. ${ }^{70-73,75}$ A reduction in the dosing interval from 14 to 12 days was sufficient to maintain the levels of eculizumab necessary to completely block intravascular hemolysis in patients who experienced breakthrough hemolysis in the last days of the dosing interval. ${ }^{75}$ All patients due to receive eculizumab must receive $N$. meningitidis vaccine at least two weeks prior to commencement of eculizumab. Quadrivalent, conjugated meningococcal vaccines are strongly recommended. Patients must be informed about the early clinical signs of meningococcal infections and must be closely monitored.

\section{Prevention and Treatment of Thrombosis}

The most feared complications in $\mathrm{PNH}$ and the leading cause of diseaserelated death are thromboembolic events. ${ }^{9.13}$ Based on retrospective analysis, it was recommended to use primary prophylactic oral anticoagulation in patients with a large PNH cell population..$^{16}$ In this study, no thromboembolic event occurred in patients who received primary warfarin prophylaxis, whereas the 10-year risk for thrombosis was $36.5 \%$ in patients without prophylaxis.

To study the impact of long-term eculizumab treatment on thromboembolism, the event rate in the clinical trials including the open-label extension trials was compared with the pre-treatment rate in the same patients. ${ }^{73}$ The event rate of venous or arterial thromboses prior to eculizumab was 7.37 events/100 patient-years. The most common sites were lower-extremity deep veins (18.5\%), mesenteric/ splenic veins (16.9\%), and hepatic/portal veins (16.9\%). With eculizumab treatment, the event rate dropped significantly to 1.07 events/100 patient-years $(p<0.001) .{ }^{73}$ In the subgroup of patients who had received antithrombotic treatment, the thromboembolic event rate was 10.6 per 100 patient-years before eculizumab and was reduced to 0.62 events per 100 patient-years in the same patients during eculizumab treatment. ${ }^{73}$ Therefore, long-term administration of eculizumab reduces the risk for thrombosis in $\mathrm{PNH}^{73}$

In acute thrombotic events, immediate anticoagulation with heparin should be started. Successful local or systemic thrombolytic therapy or radiological intervention has been reported in patients with acute onset of Budd-Chiari syndrome. ${ }^{79-82}$ After a thrombotic event, patients should be anticoagulated indefinitely. ${ }^{1}$

Currently, it is controversial how the results on eculizumab will change the recommendations for anticoagulant treatment in $\mathrm{PNH}$. Further studies are needed to clarify whether eculizumab can replace primary or even secondary prophlyaxis. For decision-making on primary prophylaxis, all factors such as symptoms, size of PNH clone, other thrombophilic risk factors, treatment for $\mathrm{PNH}$ (in particular eculizumab) and other concomitant medication, platelet count, age, activity level, compliance, and patient preference have to be taken into consideration.

Given the impact of thrombosis on mortality due to $\mathrm{PNH}^{9,13}$ one could expect that eculizumab treatment, by decreasing the risk for thrombosis, might increase the life expectancy of these patients.

\section{Conclusion}

Recent developments have raised expectations for patients with $\mathrm{PNH}$, and recent results on stem cell transplantation are encouraging. The approval of eculizumab made a targeted, disease-modifying treatment available that is well-tolerated and reduces hemolysis, transfusion requirements, and risk for thrombosis, and improves anemia and quality of life.

The availability of eculizumab raises a lot of new questions. Does eculizumab change the indication for allogeneic stem cell transplantation and if so how? Does eculizumab treatment prior to stem cell transplant influence outcome after stem cell transplantation. Does the drug treatment change the thrombosis prophylaxis? Could eculizumab treatment be combined with immunosuppression in patients with AA-PNH syndrome? 
Eculizumab treatment is very expensive. Further follow-up of eculizumab-treated patients and analysis of outcome with eculizumab in comparison with other approaches are needed in order to study its long-term effects and in particular its impact on long-term survival.

Well-designed clinical trials and follow-up of a large number of patients with this orphan disease by a worldwide patient registry is necessary to address these questions; in particular, the long-term follow-up of patients in an international registry can demonstrate how the recent changes in management will influence the natural history of $\mathrm{PNH}$.

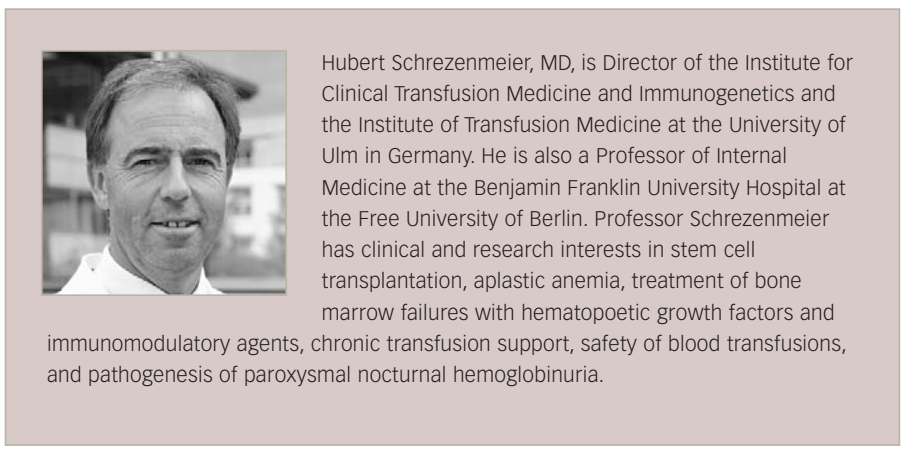

1. Parker $\mathrm{C}$, Omine $\mathrm{M}$, Richards $\mathrm{S}$, et al., Blood, 2005;106:3699-3709.

2. Luzzatto L, Curr Opin Genet Dev, 2006;16:317-22.

3. Hernandez-Campo PM, Almeida J, Acevedo MJ, et al. Transfusion, 2008;48:1403-14.

4. Richards SJ, Hillmen P, Curr Protoc Cytom, 2002;6.

5. Nebe T, Schubert J, Schrezenmeier $\mathrm{H}$, LaboratoriumsMedizin, 2003;27(7-8):257-65.

6. Araten DJ, Nafa K, Pakdeesuwan K, Luzzatto L, Proc Natl Acad Sci U S A, 1999;96:5209-14.

7. Hu R, Mukhina GL, Piantadosi S, et al., Blood 2005;105:3848-54.

8. Luzzatto L, Bessler M, Rotoli B, Cell, 1997:88:1-4.

9. de Latour RP, Mary JY, Salanoubat C, et al., Blood, 2008;112:3099-3106.

10. Nebe T, Schubert, J., Gutensohn, K., Schrezenmeier $\mathrm{H}_{\text {, J Lab }}$ Med, 2003;27:257-65.

11. Schrezenmeier $H$, Hildebrand $A$, Rojewski $M$, et al., Acta Haematol, 2000;103:41-8.

12. Moyo VM, Mukhina GL, Garrett ES, Brodsky RA, Br J Haematol, 2004;126:133-8.

13. Hillmen $\mathrm{P}$, Lewis $\mathrm{SM}$, Bessler $\mathrm{M}$, et al., N Engl I Med, 1995;333:1253-8.

14. Rosse WF, Blood, 1982;60:20-23.

15. Hartmann RC, Jenkins DE, Jr, MCKee LC, Heyssel RM, Medicine (Baltimore), 1966;45:331-63.

16. Hall C, Richards S, Hillmen P, Blood, 2003;102:3587-91.

17. Späth-Schwalbe E, Schrezenmeier H, Heimpel H, Dtsch Med Wochenschr, 1995;120:1027-33.

18. Nishimura J, Kanakura Y, Ware RE, et al., Medicine (Baltimore), 2004;83:193-207.

19. Rother RP, Bell L, Hillmen $P$, Gladwin MT, JAMA, 2005:293:1653-62.

20. Gladwin MT, Vichinsky E, N Eng/ J Med, 2008:359:2254-65

21. Kristiansen $\mathrm{M}$, Graversen $\mathrm{JH}$, Jacobsen $\mathrm{C}$, et al., Nature, 2001;409:198-201.

22. Olson JS, Foley EW, Rogge C, et al., Free Radic Biol Med, 2004;36:685-97

23. Schnog JJ, Jager EH, van der Dijs FP, et al., Ann Hematol, 2004;83:371-5

24. Hill A, Rother RP, Wang X, Blood, 2008;112:85a.

25. Catani MV, Bernassola F, Rossi A, Melino G, Biochem Biophys Res Commun, 1998;249:275-8.

26. Schrezenmeier $\mathrm{H}$, Hertenstein B, Wagner B, et al., Exp Hematol, 1995;23:81-7.

27. Schubert J, Vogt HG, Zielinska Skowronek M, et al., Blood, 1994;83:2323-8.

28. Griscelli Bennaceur A, Gluckman E, Scrobohaci ML, et al., Blood, 1995;85:1354-63.

29. Frickhofen $\mathrm{N}$, Heimpel H, Kaltwasser JP, Schrezenmeier $\mathrm{H}$, Blood, 2003;101:1236-42.

30. Mortazavi Y, Merk B, McIntosh J, et al., Blood, 2003;101:2833-41.

31. Saso R, Marsh J, Cevreska L, et al., Br J Haematol, 1999;104:392-6.

32. Sloand EM, Mainwaring L, Keyvanfar K, et al., Blood, 2004;104:3782-8.
33. Brecher ME, Taswell HF, Transfusion, 1989;29:681-5.

34. Paquette RL, Yoshimura R, Veiseh C, et al., Br J Haematol, 1997;96:92-7.

35. van $\mathrm{KH}$, van Imhoff $\mathrm{GW}$, de Wolf JT, et al., Br J Haematol, 1995;89:79-82.

36. Nakao S, Yamaguchi M, Takamatsu H, et al., Blood, 1992;80:2943-4.

37. Issaragrisil S, Piankijagum A, Am J Hematol, 1987;25:77-83

38. Bourantas K, Acta Haematol, 1994;91:62-5.

39. Erduran E, Aslan Y, Gedik Y, et al., Turk J Pediatr, 1995;37:283-7.

40. McMullin MF, Hillmen P, Elder GE, et al., Br J Haematol, 1996:92:815-17.

41. Nakakuma H, Nagakura S, Kawaguchi T, et al., Int J Hematol 1997;66:451-7.

42. Astori C, Bonfichi M, Pagnucco G, et al., Br J Haematol, 1997;97:586-8.

43. Balleari E, Gatti AM, Mareni C, et al., Haematologica, 1996;81:143-7.

44. Boschetti C, Fermo E, Bianchi P, et al., Am J Hematol, 2004;77:36-44.

45. Stebler $\mathrm{C}$, Tichelli A, Dazzi $\mathrm{H}$, et al., Exp Hematol, 1990;18:1204-8.

46. Hill A, Richards SJ, Rother RP, Hillmen P, Haematologica, 2007;92:e31-e33.

47. Schubert J, Scholz C, Geissler RG, et al., Ann Hematol, 1997;74:225-30.

48. Hill A, Ridley SH, Esser D, et al., Blood, 2006;107:2131-7

49. Spitzer $\mathrm{D}$, Unsinger J, Bessler $\mathrm{M}, \mathrm{Mol}$ Immunol, 2004;40:911-19.

50. de Latour RP, Schrezenmeier H, Mary JY, Socie G,Stem cell transplantation for paroxysmal nocurnal hemoglobinuria: an ongoing EBMT Aplastic Anemia Working Party/SFH Study, 2008.

51. Bemba M, Guardiola P, Garderet L, et al., Br J Haematol, 1999;105:366-8.

52. De Souza MH, Abdelhay E, Silva ML, et al., Bone Marrow Transplant, 1992:9:495-7.

53. Flotho C, Strahm B, Kontny U, et al., Br J Haematol, 2002;118:124-7.

54. Kawahara K, Witherspoon RP, Am J Hematol, 1992;39:283-8.

55. Raiola AM, Van Lint MT, Lamparelli T, et al., Haematologica, 2000;85:59-62.

56. Shaw PH, Haut PR, Olszewski M, Kletzel M, Pediatr Transplant, 1999; 3:315-21.

57. Lee JL, Lee JH, Lee JH, et al., Eur J Haematol, 2003;71:114-18.

58. Ditschkowski M, Trenschel R, Kummer G, et al., Bone Marrow Transplant, 2003;32:633-5.

59. Markiewicz M, Wojciechowska M, Wylezol I, et al., Ann Transplant, 2005;10:26-30.

60. Woodard P, Wang W, Pitts N, et al., Bone Marrow Transplant, 2001;27:589-92.

61. Harsdorf S, Wiesneth M, Stefanic MDC, et al., Bone Marrow Transplant, 2003:31:54.

62. Grosskreutz C, Ross V, Scigliano E, et al., Biol Blood Marrow Transplant, 2003:9:453-9.

63. Hegenbart U, Niederwieser D, Forman S, et al., Biol Blood
Marrow Transplant, 2003;9:689-97.

64. Suenaga $\mathrm{K}$, Kanda $\mathrm{Y}$, Niiya $\mathrm{H}$, et al., Exp Hematol, 2001;29:639-42.

65. Takahashi Y, McCoy JP Jr, Carvallo C, et al., Blood, 2004;103:1383-90.

66. Srinivasan R, Takahashi Y, McCoy JP, et al., Br J Haematol, 2006;133:305-14.

67. Brodsky RA, Luznik L, Bolanos-Meade J, et al., Bone Marrow Transplant, 2008;42:523-7.

68. Thomas TC, Rollins SA, Rother RP, et al., Mol Immunol, 1996;33:1389-1401.

69. Rother RP, Rollins SA, Mojcik CF, et al., Nat Biotechnol, 2007:25:1256-64.

70. Brodsky RA, Young NS, Antonioli E, et al., Blood, 2008:111:1840-47.

71. Hillmen P, Hall C, Marsh JC, et al., N Eng/ J Med, 2004;350:552-9.

72. Hillmen P, Muus P, Duhrsen U, et al., Blood, 2007;110: 4123-8.

73. Schubert J, Hillmen P, Roth A, et al., Br J Haematol, 2008 (Epub ahead of print)

74. Hillmen P, Young NS, Scuberf J et al., N Eng/ I Med, 2006;355:1233-43.

75. Hill A, Hillmen P, Richards SJ, et al., Blood, 2005;106: 2559-65.

76. Risitano AM, Marando L, Seneca E, Rotoli B, Blood, 2008;112:449-51

77. Knoll BM, Letendre L, Steensma DP, Am J Hematol, 2008:83:881-3

78. Dmytrijuk A, Robie-Suh K, Cohen MH, et al., Oncologist, 2008;13:993-1000.

79. Kuo GP, Brodsky RA, Kim HS, J Vasc Interv Radiol, 2006:17:383-7.

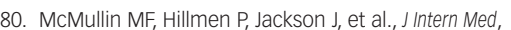
1994;235:85-9.

81. Griffith JF, Mahmoud AE, Cooper $\mathrm{S}$, et al., Clin Radiol, 1996;51:775-84.

82. Sholar PW, Bell WR, Ann Intern Med, 1985;103:539-41.

83. Schafer A, Wiesmann F, Neubauer S, et al., Circulation, 2004;109:1819-22.

84. Matejovic M, Krouzecky A, Radej J, et al., Thromb Haemost, 2007:97:304-9.

85. Olsen SB, Tang DB, Jackson MR, et al., Circulation, 1996;93:327-32.

86. Studt JD, Hovinga JA, Furlan M, Lammle B, Blood, 2003;102:1148.

87. Wiedmer T, Hall SE, Ortel TL, et al., Blood, 1993;82: $1192-6$.

88. Hugel B, Socie G, Vu T, et al., Blood, 1999;93:3451-6.

89. Gralnick HR, Vail M, McKeown LP, et al., Br J Haematol, 1995;91:697-702.

90. Ploug M, Plesner T, Ronne E, et al., Blood, 1992;79: 1447-55.

91. Grunewald $M$, Siegemund A, Grunewald A, et al., Blood Coagul Fibrinolysis, 2003;14:685-95.

92. Höchsmann B, Rojewski M, Fledel, et al., Blood, 2008;112:1180 